\title{
Scale-dependent variability of soil organic carbon coupled to land use and land cover
}

Xiong X. ${ }^{a, b}$, Grunwald S. ${ }^{a, *}$, Corstanje R. ${ }^{b}$, Yu C. ${ }^{c}$, Bliznyuk N. ${ }^{d}$

${ }^{a}$ Department of Soil and Water Science, University of Florida, Gainesville, FL 32611, USA

${ }^{\mathrm{b}}$ National Soil Resources Institute, Cranfield University, Cranfield, Bedfordskhire, MK43 OAL, UK

${ }^{c}$ College of Hydrology and Water Resource, Hohai University, Xikang Road, Nanjing, Jiangsu 210098,

China

${ }^{\mathrm{d}}$ Department of Statistics, University of Florida, Gainesville, FL 32611, USA

*Corresponding author. Telephone: +1- 352-294-3145. Fax: +1-352-392-3399. Email: sabgru@ufl.edu 


\section{Abstract:}

Understanding the field-scale spatial variability of soil organic carbon (SOC) is critical to assess its spatial distribution at very fine scale (several meters) which is valuable for precision agriculture and natural resource management. The aim of this study was to investigate the field-scale spatial variability of SOC under five prevalent land use and land cover (LULC) types in Florida, U.S. with a uniform sampling scheme . Five scales, 2, 7, 22, 67 and $>200 \mathrm{~m}$, were targeted and 108 soil samples at $0-20 \mathrm{~cm}$ depth were collected and analyzed for SOC and bulk densities within each LULC type in 2012. Results indicate that SOC variability was scale dependent. Hardwood Hammock and Forest and Improved Pasture demonstrated large variation at both coarse scale (67 and > $200 \mathrm{~m}$ ) and very fine scale $(2 \mathrm{~m})$. Sandhill, Pineland and Dry Prairie were dominated by variation at very fine scales ( 2 and $7 \mathrm{~m}$ ). All five sites showed large variability at very fine scales, indicating the close coupling of SOC stock variation to structure and composition of vegetation. This study also identified that log-transformed SOC showed variance-invariant behavior, which had an approximately constant overall variance (sill) of $0.067 \pm 0.012$ $\left(\log \left(\mathrm{kg} \mathrm{m}^{-2}\right)\right)^{2}$ at field scale $(\sim 500 \mathrm{~m})$ irrespective of LULC. These findings serve to explain field-scale variability of SOC relevant for precision agriculture and land management, but also facilitate better understanding of the scale-dependent fine-scale variability of SOC across larger soilscapes.

Keywords: soil organic carbon (SOC), field-scale spatial variability, spatially nested sampling, semivariogram, hierarchical analysis of variance. 


\section{Introduction}

In the context of sustainable agriculture and global climate change there has been great interest in soil organic carbon (SOC) (Batjes and Sombroek, 1997; Bellamy et al., 2005; Franzluebbers, 2005; Spargo et al., 2008). Globally, great efforts have been dedicated to quantifying the spatial distribution and achieving accurate assessments of SOC (Grunwald, 2009; Minasny et al., 2013). However, the current soil spatial data around the globe are at rather coarse scale (Grunwald et al., 2011). For example, in the

U.S. the major two soil databases providing readily available soil data are State Soil Geographic Database

37 (STATSGO2) and Soil Survey Geographic Database (SSURGO via Soil Data Mart) at scale of 1: 250,000 and 1:24,000, respectively. These soil databases cannot reflect SOC variation at field scale (i.e., within a few hundred meters) and provide little spatial information for precision agriculture and land management.

There have been field-scale studies of SOC variability, however they are difficult to compare because

of differences in sampling design, protocols, density of observations, sample support, carbon (C) measurement techniques, soil depth, and other factors. Even though these studies were conducted in different climatic zones, land use and land cover (LULC), soil classes, topography, and intensity of human interferences, the maximum spatial autocorrelation ranges rarely exceeded $500 \mathrm{~m}$ (Cambardella et al., 1994; Cerri et al., 2004; McBratney and Pringle, 1999; Rossi et al., 2009; Terra et al., 2004; Trangmar et al., 1987). These studies provide knowledge about the field-scale variability of SOC under specific environmental and geographic conditions. However, they lack the ability to generalize because differences in the field-scale variation of SOC may be due to methodology, SOC variation, or scaledependent relationships between SOC and other prominent environmental conditions, such as

50 topography, climate, or net ecosystem productivity (Corstanje et al., 2007; Vasques et al., 2012). Florida

51 soils hold a large amount of $\mathrm{C}$ and have great potential to accumulate more carbon. According to the

52 estimates of SOC based on the State Soil Geographic database (STATSGO) by Vasques et al. (2010), 
Florida has the highest SOC stock value per unit area among the conterminous U.S. states with minimum,

54 median, and maximum values of $12.4,35.3$, and $64.0 \mathrm{~kg} \mathrm{~m}^{-2}$, respectively. In addition, Florida enjoys a wide variety of LULC classes unique to the Southeastern U.S. and SOC stocks can vary dramatically among ecosystems (Vasques et al., 2012; Xiong et al., 2014). However, little effort has been dedicated to

57 the understanding of fine-scale spatial variability of SOC within and across different LULC types in this 58 region.

59 Various sampling designs to investigate scale dependent variation of SOC that minimizes sampling 60 effort have been suggested. Youden and Mehlich (1937) introduced a spatially nested sampling design

61 to study soil spatial variation over multiple magnitudes of scales cost-effectively compared with

62 systematic or random sampling techniques. Webster et al. (2006) formulated the theory of this

63 technique. They successfully applied both balanced and unbalanced spatial nested sampling schemes to

64 study various soil properties and reported the unbalanced design had comparable performance to the 65 balanced one with much fewer samples and better distribution of degrees of freedom across scales. Lark

66 (2011) then explored the scope for optimization of the unbalanced spatially nested design using

67 simulated annealing and claimed that the optimization can theoretically yield better estimation of

68 74 scale.

75

variance components (i.e., smaller variance of estimation) given a fixed number of samples and scales.

The major objective of this study was to investigate the field-scale variability of SOC under five common LULC classes in Florida with a uniform spatially nested sampling scheme. The specific objectives were to (i) investigate and compare the spatial structures of SOC in five LULC classes at field-scale $(<500$ m); (ii) identify the scale-dependent behavior and the controlling factors of SOC variation, and (iii) obtain an average semivariogram to capture the general characteristics of the SOC spatial variability at field

\section{Materials and methods}




\section{$78 \quad$ 2.1. Description of study areas}

The study areas are located in Florida, a state in Southeastern U.S., with latitudes from $24^{\circ} 27^{\prime} \mathrm{N}$ to

$8131^{\circ} 00^{\prime} \mathrm{N}$ and longitudes from $80^{\circ} 02^{\prime} \mathrm{W}$ to $87^{\circ} 38^{\prime} \mathrm{W}$. The climate of Northern and Central Florida is

82 humid, subtropical and Southern Florida has tropical climate. The mean annual precipitation of Florida is

$831,373 \mathrm{~mm}$ and the mean annual temperature is $22.3^{\circ} \mathrm{C}$ (National Climatic Data Center, 2008). Overall,

84 soils in Florida are sandy in texture. Dominant soil orders of Florida are: Spodosols (Podzols in World

85 Reference Base for Soil Resources , 29\%), Entisols (Fluvisol, 20\%), Ultisols (Acrisol, 17\%), Alfisols (Luvisols,

$8612 \%$ ) and Histosols (Histosols, 10\%) as shown in Fig. 1 (Natural Resources Conservation Service, 2009).

87 Florida's topography is muted with gentle slopes varying from 0 to $5 \%$ in almost the whole state (United 88 States Geological Survey, 1999).

89 To investigate the field-scale variation of SOC under different LULC, five of the most prevalent and contrasting LULC classes in Florida were selected for sampling, namely Pineland (accounting for 15.5\% of

91 the total area of Florida), Improved Pasture (7.0\%), Dry Prairie1 (2.9\%), Hardwood Hammock and Forest

92 (2.3\%), and Sandhill (1.8\%) (Florida Fish and Wildlife Conservation Commission, 2003). In total, the

93 selected LULC classes account for approximately $36 \%$ of the Florida land area (excluding open water

94 areas). Spatially, the five sites are spread out across Florida as shown in Fig. 1. The soil properties and 95 environmental conditions of the five sites are summarized in Table 1.

\section{$97 \quad$ 2.2. Optimized unbalanced spatially nested sampling}

\footnotetext{
${ }^{1}$ The definition of Dry Prairie adopted in this study is a large native grass and shrubland occurring on very flat terrain interspersed with scattered cypress domes and strands, bayheads, isolated freshwater marshes, and hardwood hammocks, according to Florida Fish and Wildlife Conservation Commission (2003)
} 
99 At each of the five LULC sites, the same sampling scheme and protocol were used. The sampling 100 followed an optimized unbalanced spatially nested design. The theory of the spatially nested design can 101 be found in Webster et al. (2006) and the optimization of the design in Lark (2011). Five levels of

102 hierarchy were studied (Table 2) and a detailed account of the design is described as follows. Nine main 103 stations gridded at $200 \mathrm{~m}$ intervals constitute Level 1(Fig. 2a). At each main station, two additional 104 sampling points (subnodes) were chosen $67 \mathrm{~m}$ away and form an equilateral triangle with the main 105 station sampling point. The equilateral triangle is placed in a random direction. Then in similar fashion 106 the 3rd, 4th and 5th hierarchical samples were sampled $22 \mathrm{~m}, 7 \mathrm{~m}$ and $2 \mathrm{~m}$ away from their parent 107 nodes, respectively. The approximate three-fold hierarchy has proven effective in capturing as much 108 variation as possible and avoiding overlaps among different branches (Webster et al., 2006). Fig. 2b 109 shows the sample deployment of one main station. A number of $108(9 \times 12)$ samples were collected 110 within each LULC resulting in a total number of 540 samples for the five sites.

\subsection{Soil sampling and laboratory analysis}

Predetermined sample locations were identified with a sub-meter accuracy global positioning system

115 (Trimble GeoXT 2005 series). Soil samples were collected with a 5.7-cm-diameter-steel core at 0-20 cm 116 depth. Soil samples were put into sample bags and transported to the laboratory in coolers at $0^{\circ} \mathrm{C}$. Then 117 samples were air dried, weighted, sieved through a 2-mm sieve, and ball milled. Total carbon (TC) was 118 analyzed by combustion catalytic oxidation at $900^{\circ} \mathrm{C}$ (Shimadzu SSM-5000A). Considering that the 119 topsoil in Florida contains little inorganic carbon, a pedotransfer function developed for Florida soils was 120 used to derive SOC (Vasques et al., 2009). The pedotransfer function is: SOC (\% mass) $=0.9977 \times$ TC $(\%$ 121 mass $)-0.0389\left(n=1,080, R^{2}=0.999\right)$. Laboratory SOC measurements in mass units $\left(\mathrm{mg} \mathrm{kg}^{-1}\right)$ were 
122 converted to stock units $\left(\mathrm{kg} \mathrm{m}^{-2}\right)$ using the measured bulk density and soil depth $(20 \mathrm{~cm})$. The SOC data

123 in the five LULC classes were positively skewed; hence they were log-transformed to approximate

124 normal distribution and stabilize the variance for the statistical and geostatistical analyses. In this study,

125 the soil bulk density was homogeneous within each site as indicated by the small standard deviation in

126 Table 1 (range from 0.07 to $0.11 \mathrm{~g} \mathrm{~cm}^{-3}$ ). Therefore, its contribution to SOC stock uncertainty was

127 negligible (Taalab et al., 2013).

128

\subsection{Hierarchical analysis of variance}

130

To estimate the variance components of SOC at the five scales, the linear mixed model was used (Eq.

132 1)

133

$Z_{i j k l m n}=\mu+A_{i}+B_{i j}+C_{i j k}+D_{i j k l}+E_{i j k l m}+\varepsilon_{i j k l m n}$

134 where, $Z_{i j k l m n}$ is the log-transformed SOC value of the $n$th sampling point in the $m$ th class at Level 5 , in

135 the /th class at Level $4, \ldots$ the ith class at Level $1, \mu$ is the overall mean of the log-transformed SOC at one 136 site, $A_{i}$ is the difference between mean of the ith main station and the overall mean $\mu$, and is an

137 identically and independently distributed random variable with mean zero and variance $\sigma_{A}^{2}, B_{i j}$ is the 138 difference between the mean of the $j$ th class within the ith main station and the mean of the $i$ th main 139 station, and is an identically and independently distributed random variable with mean zero and 140 variance $\sigma_{B}^{2}$, and so on. The error term is represented by $\varepsilon_{i j k l m n}$. In this case, there is only one fixed 141 effect, which is the overall mean $\mu$, while the five random effects represent the five scales. To estimate 142 the variance components, $\sigma_{A}^{2}, \sigma_{B}^{2}, \ldots, \sigma_{E}^{2}$ from the data with an unbalanced design, restricted maximum 143 likelihood (REML) was used with the assumption of normally distributed random effects (Webster et al., 144 2006). The likelihood ratio test was used to test the significance of a variance component by comparing 145 the full model (Eq. 1) and the model with the random effect removed from the full model (Bates, 2010). 
$151 \hat{\gamma}(h)=\frac{1}{2}\left(\frac{1}{N(h)} \sum_{N(h)}\left|Z\left(s_{i}\right)-Z\left(s_{j}\right)\right|^{1 / 2}\right)^{4} /\left(0.457+\frac{0.494}{N(h)}\right)$

152 where, $N(h)$ is the number of data pairs separated by a distance of $h, Z\left(s_{i}\right)$ and $Z\left(s_{j}\right)$ are the SOC

153 observation at location $s_{i}$ and $s_{j}$ respectively.

154 The Matérn theoretical semivariogram model (Eq. 3) was fitted the experimental semivariogram with 155 REML. It generalizes a variety of semivariogram models and has a smoothness parameter that can be 156 used to infer short-range variation (Minasny and McBratney, 2005).

$157 \quad \gamma(h)=\tau^{2}+\sigma^{2}\left(\frac{1}{2^{v-1} \Gamma(v)}\left(\frac{h}{\varphi}\right)^{v} K_{v}\left(\frac{h}{\varphi}\right)\right)$

158 where, $\tau^{2}$ is the nugget, $\sigma^{2}$ is the partial sill, $h$ is the lag distance, $K_{v}$ is a modified Bessel function of the 159 second kind of order $v, \Gamma$ is the gamma function and $\varphi$ is the range parameter and $v$ is the smoothness 160 parameter.

161 The Matérn model generalizes a variety of semivariogram models and has a smoothness parameter 162 that can be used to infer the short-range variation (Minasny and McBratney, 2005).

\subsection{Average semivariogram}


average SOC semivariogram, the spatial linear mixed model (Eq. 4) was applied on the pooled five-site

170 dataset.

$171 \quad \mathbf{Y}=\mathbf{X} \boldsymbol{\beta}+\boldsymbol{\varepsilon} \quad(4)$

172 where, $\mathbf{Y}$ is an $n \times 1$ vector of observed SOC values, $\mathbf{X}$ is a $n \times 5$ dummy coded design matrix of five

173 LULC classes (fixed effects), $\boldsymbol{\beta}$ is the vector of fixed-effect coefficients, and $\boldsymbol{\varepsilon}$ is an $n \times 1$ vector of errors.

174 Two methods were used to estimate the model parameters. The first method used ordinary least

175 squares (OLS) to estimate $\boldsymbol{\beta}$ by assuming $\boldsymbol{\varepsilon}$ to be identically and independently distributed random

176 variables of mean zero and variance $\sigma^{2}$, i.e., $\boldsymbol{\varepsilon} \sim N\left(0, \sigma^{2} \mathbf{I}\right)$, where $\mathbf{I}$ is the identical matrix. The second

177 method used generalized least squares (GLS) to estimate $\boldsymbol{\beta}$ by taking the correlation among errors into

178 account, i.e., $\boldsymbol{\varepsilon} \sim N(0, \mathbf{V})$, where $\mathbf{V}$ is the variance-covariance matrix of error variables that were

179 estimated with REML (Lark and Cullis, 2004). The likelihood ratio test was used to test whether the GLS

180 model is significantly better than the OLS model (Bates, 2010).

181

182 3. Results

183

184

\subsection{Descriptive statistics of soil organic carbon}

The mean SOC varied greatly across the five LULC classes. Dry Prairie, Hardwood Hammock and

187 Forest, and Improved Pasture had relatively high SOC stocks, while Sandhill and Pineland soil had

188 relatively low SOC (Table 1). Linking the SOC means of the five sites with the edaphic and environmental

189 conditions reveals the underlying controls of SOC levels across different LULC classes. Improved Pasture,

190 although very high in soil available water capacity (AWC), is inclined to accumulate SOC. However, it

191 ranked just as intermediate in the sequence of LULC classes in terms of accumulation of SOC due to the

192 moderate net primary productivity (NPP) in the Improved Pasture system, which provided moderate C 
input into soils. Sandhill had low AWC and low NPP and thus had very limited ability to sequester soil C.

194 In contrast, Dry Prairie and Hardwood Hammock and Forest were high in both AWC and NPP and 195 therefore tended to accumulate SOC.

196 The standard deviation of SOC also showed differences across the five LULC classes. Hardwood

197 Hammock and Forest had the largest overall variation of SOC, followed by Dry Prairie and Improved 198 Pasture, while Sandhill and Pineland showed modest variation. The coefficient of variation reflected that 199 the overall variation generally increased with the average SOC stock, which results in a similar variation 200 of SOC across the five sites. There was a significant linear correlation at 0.05 significance level ( $p$-value $=$ 201 0.021) between the variance and the squared mean of SOC (Fig. 3a). After natural log-transformation 202 the variance was stabilized as indicated by Fig. 3b.

\subsection{Hierarchical analysis of variance of soil organic carbon}

205

Variations of SOC in the five LULC classes were scale dependent (Fig. 4). In Sandhill, the largest variance components were found at finest scales ( 7 and $2 \mathrm{~m}$ ), whereas variations at coarser scale, 22, 67 and $>200 \mathrm{~m}$, were negligible. Hardwood Hammock and Forest had the most variation at the coarsest scale (> $200 \mathrm{~m}$ ) and the finest scale $(2 \mathrm{~m})$ also accounted for a large portion of the overall SOC variation.

210 The variation at $7 \mathrm{~m}$ was also noticeable compared with the variations at $22 \mathrm{~m}$ and $67 \mathrm{~m}$ which were 211 almost negligible. In Pineland, the finest scale variation was markedly greater than the other scales

212 indicating most variation in Pineland occurred within $2 \mathrm{~m}$. In Improved Pasture, the change of variation 213 across scales was less prominent than those in other LULC classes. The relatively large variation

214 stemmed from the coarsest scales $(67$ and $>200 \mathrm{~m}$ ) followed by the finest scale variation. Similar to 215 Sandhill and Pineland, Dry Prairie had the largest variance components at 2 and $7 \mathrm{~m}$ indicating that fine216 scale variation dominated the variation under this LULC. 


\subsection{Semivariogram analysis of soil organic carbon}

To complement the hierarchical analysis of variance, semivariogram analysis was conducted and the

221 results are shown in Table 4 and Fig. 5.

222 The sampled SOC of five sites showed distinct spatial structures. Improved Pasture showed strong 223 spatial dependence (0.85), followed by Sandhill (0.37), Hardwood Hammock and Forest (0.37), and Dry

224 Prairie (0.35) with moderate spatial dependence, whereas Pineland showed no clear spatial structure 225 (Table 4). The effective spatial autocorrelation ranges of the five sites varied dramatically from site to 226 site. Large ranges were observed in Hardwood Hammock and Forest (effective range: $391.2 \mathrm{~m}$ ) and 227 Improved Pasture $(348.0 \mathrm{~m})$ compared with small ranges in Sandhill (11.5 m) and Dry Prairie $(23.4 \mathrm{~m})$.

228 These ranges were smaller than one-third of the sampling extent ( $500 \mathrm{~m}$ ) indicating stationarity in SOC 229 within each of the fields. The smoothness parameter $v$ is an important factor that not only measures the 230 smoothness of the SOC processes but is also helpful in inferring short-range variation. The nugget

231 variance is the combination of measurement errors and short-range spatial variation that occurs within 232 the shortest sampling distance, i.e., $2 \mathrm{~m}$ in this study. The smoother the processes to accrete or deplete 233 soil carbon, the less likely that short-range variation occurred. These processes of gaining or losing SOC 234 under Hardwood Hammock and Forest were quite smooth $(v=99.0)$ approximating a Gaussian model 235 (Fig. 5). In contrast, Dry Prairie and Improved Pasture had relative rough processes of aggregating SOC 236 stocks suggesting that short-range variation prevailed under these two LULC classes. 
The average semivariogram of the five sites had a smooth parameter close to 0.5 , which indicates an approximate exponential semivariogram model. It had a relatively long range of $\sim 100 \mathrm{~m}$ and moderate 242 spatial dependence of 0.4 .

243 Table 5 compares the results of two ANOVA models - one using OLS that renders samples as

244 independent of each other and the other one using GLS that accounts for the autocorrelation. The result 245 shows that accounting for the autocorrelation significantly improved the model $(p$-value $<0.0001)$,

246 which justifies the two degrees of freedom used to estimate the two autocorrelation parameters (range 247 and nugget). Estimates of SOC mean for each LULC from OLS are the arithmetic mean of corresponding 248 samples, while GLS gave slightly larger estimates except for Improved Pasture. More importantly, the 249 results of post hoc pair-wise comparisons from the two models are distinctly different. Ordinary least 250 squares tended to reject the null hypothesis based on underestimated variance of SOC in each LULC, 251 therefore ordered the mean SOC of the five LULC as: Dry Prairie $\cong$ Hardwood Hammock and Forest > 252 Improved Pasture $>$ Pineland $>$ Sandhill. In contrast, GLS detected no difference between Pineland and 253 Sandhill, Pineland and Improved Pasture, and Dry Prairie and Improved Pasture. Because the samples 254 are spatially correlated, it is necessary to account for the spatial autocorrelation among samples when 255 analyzing the fixed effect of LULC on SOC stock and estimating the mean SOC stock in the LULC.

\section{4. Discussion}

To the best of our knowledge, this is the first study to compare the field-scale variability of SOC of

260 prevalent LULC classes in the southeastern landscape of the U.S. under a unified framework (i.e., 261 standardized protocol, sampling design and models). This study demonstrates that the spatial 262 heterogeneity of SOC in different LULC showed both similarities and differences which may be 263 attributed to both natural processes and anthropogenic interference. 
The heterogeneity in SOC is known to be primarily controlled by soil water content, vegetation, 265 climate, and topography (Guo et al., 2006; Liu et al., 2006; Vasques et al., 2010; Xiong et al., 2014). Human activities such as land use, have been recognized as an important soil forming factor that exerts

267 great influence on SOC variation (Guo and Gifford, 2002; Maia et al., 2010; Murty et al., 2002). The 268 controls of these factors on SOC variability are known to operate at various scales corresponding to the 269 scales of variability of the factors per se (Grunwald et al., 2011; Vasques et al., 2012). For example, 270 annual precipitation and temperature show variation at regional scale rather than at field-scale.

271 Therefore, climate is a confounding factor affecting the field-scale variability of SOC in this study. The 272 topography in Florida is generally flat with pronounced interspersed micro-depressions. This micro273 topography can dictate soil water content (e.g., toposequence) and result in dramatically different SOC 274 accumulation (Kamara et al., 2007).

\subsection{Scale-dependent variability of SOC and the controlling factors}

In Sandhill, the vegetation was dominated by an overstory of scattered longleaf pines (Pinus palustris)

279 ( $\sim 10 \mathrm{~m}$ average spacing), along with an understory of oak trees (Quercus). The space between trees was filled by various herbs and grasses. This vegetation pattern coinciding at about $10 \mathrm{~m}$ scale explains the 281 largest variance components of SOC that was found at 7 and $2 \mathrm{~m}$ scale (Fig. 4) and the short range of 282 autocorrelation (Fig. 5). There were limited land management practices that had occurred at the 283 Sandhill site, suggesting that the native spatial structure of SOC that was formed by natural ecosystem 284 processes was not disturbed. This indicates that the vegetation was the only major controller of the 285 spatial heterogeneity of SOC. In Pineland, the vegetation was exclusively longleaf pine trees ( $2 \mathrm{~m}$ average spacing) that were planted in form of commercial stands converted from non-native slash pines

287 (Pinus elliottii) approximately five years ago. The commercial pine plantation operation had altered 
greatly the native spatial structure of SOC under pine forest, which is evidenced by the lack of spatial autocorrelation at the Pineland site (Fig. 5). The largest variance component at $2 \mathrm{~m}$ indicates that the restored longleaf pine exerted influence on the spatial heterogeneity of SOC within $2 \mathrm{~m}$. In Dry Prairie,

291 the native vegetation was dominated by saw palmettos (Serenoa repens) ( $1 \mathrm{~m}$ average spacing)

292 sparsely intermixed with various grasses, sedges herbs and shrubs (e.g., Leucothoe fontanesiana,

293 Aristida beyrichiana, Axonopus fissifolius, Vaccinium formosum). This site had been maintaining the

294 natural conditions with limited human interferences and was subject to lightning-induced fires and

295 seasonal flooding that controlled the ever-invading woody plants. Therefore, the short range of spatial

296 autocorrelation and the largest variance components found at the finest scales ( 2 and $7 \mathrm{~m})$ were

297 primarily in accordance to the spatial distribution pattern of saw palmettos. In Hardwood Hammock and

298 Forest the vegetation was more diverse in species than the other LULC and the spatial distribution of

299 species coincided with the soil moisture regimes - hardwoods predominantly found in wetter areas and

300 pine trees in well-drained areas. This spatial pattern of vegetation species accounted for the large

301 variation at the coarsest scale (>200 m) and the influence of individual trees explained the large

302 variation at $2 \mathrm{~m}$. In Improved Pasture, the soil was heavily managed. The site had been cleared, tilled,

303 reseeded with forage grass and applied with fertilizer periodically. Besides, some areas were more

304 heavily frequented by cattle flocks than other areas, which resulted in spatial variation of manure input

305 and grass consumption. These practices may have determined the strong spatial structure of SOC

306 observed in this study, similar to the findings by (Zhang et al., 2012).

307 The spatial structures of the topsoil SOC under five common LULC in Florida from this study show 308 similarities compared to other studies. Rossi et al. (2009) applied a similar nested sampling design to 309 investigate the spatial variation of topsoil SOC in tropical forests in Southeastern Tanzania. They also 310 found that under pine plantation, there was no spatial autocorrelation due to human management 311 activities, while the spatial structures of SOC in other natural forests were pronounced. Their results also 
312 suggest that in forests, where the vegetation composition and structure were more complex, the ranges

313 of spatial autocorrelation were larger, which is confirmed by this present study (Hardwood Hammock

314 and Forest). Cambardella et al. (1994) studied the field-scale variability of SOC in two farms of Central

315 lowa and observed similar spatial structure to that of Improved Pasture from this study with observed

316 ranges between 104 and $129 \mathrm{~m}$ with strong spatial dependence. This may be because the agricultural

317 practices, such as tilling, weed control and fertilizing, are similar between the two studies and resulted

318 in similar impact on the spatial structure of SOC. Cerri et al. (2004) used a systematic sampling design

319 with a $25 \mathrm{~m}$ grid to study the spatial variation of soil total carbon in an Amazon pasture and also

320 observed relatively large nugget effects accounting for 85 and $73 \%$ of the overall variances at $0-10 \mathrm{~cm}$

321 and $10-20 \mathrm{~cm}$ respectively. Their result suggested that large variability existed either within $25 \mathrm{~m}$ and

322 the measurement error. These similarities of SOC spatial structures from distinct studies suggest that

323 the spatial structure model obtained at the five sites may apply to other sites with the same or similar

324 land use and management practices at field scale ( 500 m).

325

\subsection{Average semivariogram and its utilities}

The average semivariogram (Fig. 5) derived by pooling the data of five sites together provides a

329 general picture of the field-scale spatial structure of SOC. The model is comparable to the average SOC

330 semivariogram reported by McBratney and Pringle (1999) who gathered a set of field-scale

331 semivariograms from nine studies and obtained an average semivariogram for soil carbon. Despite the

332 difference in the models used to fit the semivariogram, the spatial structure is fairly similar between the

333 two studies. This similarity suggests the generality in the average semivariogram model of SOC at the

334 scale of $\sim 500 \mathrm{~m}$ regardless of the different edaphic and environmental conditions between the two

335 studies. It has been well known that SOC follows a log-normal distribution and log-transformation is a 
common practice to normalize SOC data (Orton et al., 2014; Vasques et al., 2012). Furthermore, there

337 exists proportionality between the variance and the squared mean of SOC (Fig. 3). The proportionality ensures that log-transformed SOC data has approximately constant variance (Carroll and Ruppert, 1988).

This variance-invariant property suggests that SOC should display similar overall variance (sill) of $0.067 \pm$

$0.012\left(\log \left(\mathrm{kg} \mathrm{m}^{-2}\right)\right)^{2}$ at field scale $(<500 \mathrm{~m})$ irrespective of LULC, which explains an important facet of the generality of the SOC average semivariogram derived in this study. The SOC average semivariogram can be readily used as prior knowledge of the soil carbon variability at field scale.

Another important utility of the average semivariogram is in modeling the effects of various environmental factors and forcings (fixed effects) on SOC. Any spatial sampling design can barely avoid the autocorrelation among samples, especially at field scale. Therefore, it is desirable to account for the spatial autocorrelation among samples when estimating the parameters of the fixed effects. The average semivariogram is of great value for more accurate modeling of soil processes.

\section{Conclusions}

This study investigated the field-scale variability $(<500 \mathrm{~m})$ of SOC at $0-20 \mathrm{~cm}$ in five prevalent LULC classes in Florida, U.S. under a uniform framework - same sampling design, size, sample support, and data analysis methods - allowing an intra- and inter-comparison among fields. The field-scale variability of SOC was scale-dependent and tightly coupled to LULC types and the vegetation composition and structure. The average semivariogram depicted the overall spatial variability of SOC at field scale with the range parameter of $\sim 100 \mathrm{~m}$, moderate spatial dependence $(0.4)$ and a smoothness parameter of

$357 \sim 0.5$. The variance-invariant property of log-transformed SOC indicates that SOC displays similar overall 
360 management, but also facilitate better understanding of the scale-dependent fine-scale variability of

361 SOC across larger soilscapes. 


\section{Acknowledgements}

363

364 This study was funded as part of a larger USDA-CSREES-NRI grant award 2007-35107-18368 'Rapid

365 Assessment and Trajectory Modeling of Changes in Soil Carbon across a Southeastern Landscape'

366 (National Institute of Food and Agriculture (NIFA) - Agriculture and Food Research Initiative (AFRI)). This

367 project is a Core Project of the North American Carbon Program. We are grateful to Dr. Murray Lark

368 (British Geological Survey, UK) for his help in optimizing the spatially nested sampling scheme. We also

369 thank Ce Yang, Christopher Wade Ross, Baijing Cao, Jongsung Kim, and Pasicha Chaikaew (University of

370 Florida) for their assistance in field sampling and laboratory analyses. 


\section{References}

Bates, D.M., 2010. Ime4: Mixed-effects modeling with R. Springer US.

Batjes, N.H., Sombroek, W.G., 1997. Possibilities for carbon sequestration in tropical and subtropical soils. Glob. Change Biol. 3, 161-173. doi:10.1046/j.1365-2486.1997.00062.x

Bellamy, P.H., Loveland, P.J., Bradley, R.I., Lark, R.M., Kirk, G.J.D., 2005. Carbon losses from all soils across England and Wales 1978-2003. Nature 437, 245-248. doi:10.1038/nature04038

Cambardella, C.A., Moorman, T.B., Parkin, T.B., Karlen, D.L., Novak, J.M., Turco, R.F., Konopka, A.E., 1994. Field-scale variability of soil properties in Central lowa soils. Soil Sci. Soc. Am. J. 58, 15011511. doi:10.2136/sssaj1994.03615995005800050033x

Carroll, R.J., Ruppert, D., 1988. Transformation and weighting in regression. Chapman and Hall/CRC, New York, USA.

Cerri, C.E.P., Bernoux, M., Chaplot, V., Volkoff, B., Victoria, R.L., Melillo, J.M., Paustian, K., Cerri, C.C., 2004. Assessment of soil property spatial variation in an Amazon pasture: Basis for selecting an agronomic experimental area. Geoderma 123, 51-68. doi:10.1016/j.geoderma.2004.01.027

Corstanje, R., Schulin, R., Lark, R.M., 2007. Scale-dependent relationships between soil organic carbon and urease activity. Eur. J. Soil Sci. 58, 1087-1095. doi:10.1111/j.1365-2389.2007.00902.x

Cressie, N.A.C., 1993. Statistics for spatial data, Revised edition. ed. Wiley, New York.

Florida Fish and Wildlife Conservation Commission (FFWCC), 2003. Florida vegetation and land cover data derived from Landsat ETM+ imagery.

Franzluebbers, A.J., 2005. Soil organic carbon sequestration and agricultural greenhouse gas emissions in the southeastern USA. Soil Tillage Res. 83, 120-147. doi:10.1016/j.still.2005.02.012

Grunwald, S., 2009. Multi-criteria characterization of recent digital soil mapping and modeling approaches. Geoderma 152, 195-207. doi:10.1016/j.geoderma.2009.06.003

Grunwald, S., Thompson, J.A., Boettinger, J.L., 2011. Digital soil mapping and modeling at continental scales: Finding solutions for global issues. Soil Sci. Soc. Am. J. 75, 1201-1213. doi:10.2136/sssaj2011.0025

Guo, L.B., Gifford, R.M., 2002. Soil carbon stocks and land use change: A meta analysis. Glob. Change Biol. 8, 345-360. doi:10.1046/j.1354-1013.2002.00486.x

Guo, Y., Gong, P., Amundson, R., Yu, Q., 2006. Analysis of factors controlling soil carbon in the conterminous United States. Soil Sci. Soc. Am. J. 70, 601. doi:10.2136/sssaj2005.0163

Kamara, A., Rhodes, E.R., Sawyerr, P.A., 2007. Organic carbon dynamics along a toposequence in a peri-urban site. Commun. Soil Sci. Plant Anal. 38, 2371-2379. doi:10.1080/00103620701588502

Lark, R.M., 2011. Spatially nested sampling schemes for spatial variance components: Scope for their optimization. Comput. Geosci. 37, 1633-1641. doi:10.1016/j.cageo.2010.12.010

Lark, R.M., Cullis, B.R., 2004. Model-based analysis using REML for inference from systematically sampled data on soil. Eur. J. Soil Sci. 55, 799-813. doi:10.1111/j.1365-2389.2004.00637.x

Liu, D., Wang, Z., Zhang, B., Song, K., Li, X., Li, J., Li, F., Duan, H., 2006. Spatial distribution of soil organic carbon and analysis of related factors in croplands of the black soil region, Northeast China. Agric. Ecosyst. Environ. 113, 73-81. doi:10.1016/j.agee.2005.09.006

Maia, S.M.F., Ogle, S.M., Cerri, C.E.P., Cerri, C.C., 2010. Soil organic carbon stock change due to land use activity along the agricultural frontier of the southwestern Amazon, Brazil, between 1970 and 2002. Glob. Change Biol. 16, 2775-2788. doi:10.1111/j.1365-2486.2009.02105.x

McBratney, A.B., Pringle, M.J., 1999. Estimating average and proportional variograms of soil properties and their potential use in precision agriculture. Precis. Agric. 1, 125-152. doi:10.1023/A:1009995404447

Minasny, B., McBratney, A.B., 2005. The Matérn function as a general model for soil variograms. Geoderma 128, 192-207. doi:10.1016/j.geoderma.2005.04.003 
Minasny, B., McBratney, A.B., Malone, B.P., Wheeler, I., 2013. Digital mapping of soil carbon, in: Donald L. Sparks (Ed.), Advances in Agronomy. Academic Press, pp. 1-47.

Murty, D., Kirschbaum, M.U.F., Mcmurtrie, R.E., Mcgilvray, H., 2002. Does conversion of forest to agricultural land change soil carbon and nitrogen? A review of the literature. Glob. Change Biol. 8, 105-123. doi:10.1046/j.1354-1013.2001.00459.x

National Climatic Data Center (NCDC), National Oceanic and Atmospheric Administration (NOAA), 2008. Monthly surface data.

Natural Resources Conservation Service (NRCS), U.S. Department of Agriculture, 2009. Soil Survey Geographic Database (SSURGO).

Orton, T.G., Pringle, M.J., Page, K.L., Dalal, R.C., Bishop, T.F.A., 2014. Spatial prediction of soil organic carbon stock using a linear model of coregionalisation. Geoderma 230-231, 119-130. doi:10.1016/j.geoderma.2014.04.016

Rossi, J., Govaerts, A., De Vos, B., Verbist, B., Vervoort, A., Poesen, J., Muys, B., Deckers, J., 2009. Spatial structures of soil organic carbon in tropical forests-A case study of Southeastern Tanzania. Catena 77, 19-27. doi:10.1016/j.catena.2008.12.003

Spargo, J.T., Alley, M.M., Follett, R.F., Wallace, J.V., 2008. Soil carbon sequestration with continuous notill management of grain cropping systems in the Virginia coastal plain. Soil Tillage Res. 100, 133-140. doi:10.1016/j.still.2008.05.010

Taalab, K.P., Corstanje, R., Creamer, R., Whelan, M.J., 2013. Modeling soil bulk density at the landscape scale and its contributions to $C$ stock uncertainty. Biogeosciences 10, 4691-4704. doi:10.5194/bg-10-4691-2013

Terra, J.A., Shaw, J.N., Reeves, D.W., Raper, R.L., Van Santen, E., Mask, P.L., 2004. Soil carbon relationships with terrain attributes, electrical conductivity, and a soil survey in a coastal plain landscape. Soil Sci. 169, 819-831.

Trangmar, B.B., Yost, R.S., Wade, M.K., Uehara, G., Sudjadi, M., 1987. Spatial variation of soil properties and rice yield on recently cleared land. Soil Sci. Soc. Am. J. 51, 668-674. doi:10.2136/sssaj1987.03615995005100030021x

United States Geological Survey (USGS), 1999. National Elevation Dataset (NED).

Vasques, G.M., Grunwald, S., Comerford, N.B., Sickman, J.O., 2010. Regional modelling of soil carbon at multiple depths within a subtropical watershed. Geoderma 156, 326-336. doi:10.1016/j.geoderma.2010.03.002

Vasques, G.M., Grunwald, S., Myers, D.B., 2012. Associations between soil carbon and ecological landscape variables at escalating spatial scales in Florida, USA. Landsc. Ecol. 27, 355-367. doi:10.1007/s10980-011-9702-3

Webster, R., Welham, S.J., Potts, J.M., Oliver, M.A., 2006. Estimating the spatial scales of regionalized variables by nested sampling, hierarchical analysis of variance and residual maximum likelihood. Comput. Geosci. 32, 1320-1333. doi:10.1016/j.cageo.2005.12.002

Xiong, X., Grunwald, S., Myers, D.B., Kim, J., Harris, W.G., Comerford, N.B., 2014. Holistic environmental soil-landscape modeling of soil organic carbon. Environ. Model. Softw. 202-215. doi:10.1016/j.envsoft.2014.03.004

Youden, W.J., Mehlich, A., 1937. Selection of efficient methods for soil sampling. Contrib. Boyce Thompson Inst. Plant Res. 9, 59-70.

Zhang, W., Weindorf, D.C., Zhu, Y., Haggard, B.J., Bakr, N., 2012. Anthropogenic Management Impact on Soil Organic Carbon Variability: A Case Study in Louisiana, USA. Soil Horiz. 53, 18-22.

Table 1. Summary of soil properties and environmental conditions of the five sampling sites. 


\begin{tabular}{lllllllll}
\hline Sites & Soil & Bulk density $(\mathrm{SD})^{\mathrm{a}}$ & Precip. & Temp. & Elevation & Slope & NPP & AWC25 \\
\cline { 5 - 8 } & suborder & $\mathrm{g} \mathrm{cm}^{-3}$ & $\mathrm{~mm}$ & ${ }^{\circ} \mathrm{C}$ & $\mathrm{m}$ & $\%$ & $\mathrm{~kg} \mathrm{C} \mathrm{m}^{-2}$ & $\mathrm{~cm} \mathrm{~cm}^{-1}$ \\
\hline SH & Psamments & $1.42(0.07)$ & 1325 & 20.8 & 42.8 & 1.15 & 7.91 & 1.22 \\
$\mathrm{HHF}$ & Aquults & $1.22(0.11)$ & 1344 & 20.5 & 43.5 & 1.20 & 13.58 & 2.12 \\
$\mathrm{PL}$ & Psamments & $1.40(0.08)$ & 1634 & 19.6 & 23.9 & 2.85 & 9.07 & 1.54 \\
$\mathrm{IP}$ & Udults & $1.56(0.09)$ & 1360 & 20.4 & 28.8 & 2.43 & 7.45 & 2.18 \\
$\mathrm{DP}$ & Aquods & $1.22(0.10)$ & 1464 & 22.7 & 8.7 & 0.15 & 8.13 & 1.66
\end{tabular}

464 Abbreviations: $\mathrm{SH}=$ Sandhill, $\mathrm{HHF}=$ Hardwood Hammock and Forest, $\mathrm{PL}=$ Pineland, IP = Improved

465 Pasture, $\mathrm{DP}=$ Dry Prairie, $\mathrm{SD}=$ standard deviation, Precip. = long term annual average precipitation

466 (1971-2000), Temp. = annual average temperature, NPP = net primary productivity, AWC25 = soil

467 available water holding capacity at 0-25 cm depth. Precip. and Temp. are from PRISM (Parameter-

468 elevation Regressions on Independent Slopes Model), NPP from MODIS (Moderate-Resolution Imaging

469 Spectroradiometer) for North American Carbon Project (date: 2005), AWC25 and AWC50 from SSURGO

470 (Soil Survey Geographic Database, date: 2009)

$471 \quad{ }^{a}$ Bulk density is the air-dried soil bulk density of the samples collected in this study, reported as mean 472 and standard deviation in the parentheses. 
473 Table 2. Hierarchy of the optimized unbalanced spatially nested scheme.

\begin{tabular}{lll}
\hline $\begin{array}{l}\text { Hierarchical } \\
\text { level }\end{array}$ & Scale & $\begin{array}{l}\text { Degrees of } \\
\text { freedom }\end{array}$ \\
\hline 1 & $>200 \mathrm{~m}$ & 8 \\
2 & $67 \mathrm{~m}$ & 18 \\
3 & $22 \mathrm{~m}$ & 36 \\
4 & $7 \mathrm{~m}$ & 27 \\
5 & $2 \mathrm{~m}$ & 18 \\
\hline
\end{tabular}

474 
475 Table 3. Descriptive statistics of soil organic carbon stock at 0-20 cm depth.

\begin{tabular}{|c|c|c|c|c|c|c|c|c|c|c|c|c|}
\hline \multirow{3}{*}{ Sites } & \multirow{3}{*}{$\mathrm{N}$} & \multicolumn{7}{|c|}{ Original } & \multicolumn{4}{|c|}{ Log-transformed } \\
\hline & & Min. & Median & Mean & Max. & SD & $\mathrm{CV}$ & Skew. & Mean & SD & $\mathrm{CV}$ & Skew. \\
\hline & & \multicolumn{5}{|c|}{$\mathrm{kg} \mathrm{m}^{-2}$} & $\%$ & & \multicolumn{2}{|c|}{$\log \left(\mathrm{kg} \mathrm{m}^{-2}\right)$} & $\%$ & \\
\hline $\mathrm{SH}$ & 108 & 0.86 & 1.49 & 1.58 & 2.87 & 0.42 & 26.6 & 0.92 & 0.42 & 0.26 & 61.9 & 0.33 \\
\hline HHF & 108 & 2.16 & 3.90 & 4.13 & 7.02 & 1.18 & 28.6 & 0.60 & 1.38 & 0.28 & 20.3 & 0.08 \\
\hline PL & 108 & 0.84 & 1.65 & 1.78 & 5.64 & 0.63 & 35.4 & 3.05 & 0.53 & 0.28 & 52.8 & 1.18 \\
\hline IP & 108 & 1.79 & 3.13 & 3.28 & 6.97 & 0.85 & 25.9 & 1.56 & 1.16 & 0.24 & 20.7 & 0.57 \\
\hline DP & 108 & 2.31 & 4.06 & 4.17 & 8.54 & 0.98 & 23.5 & 1.13 & 1.40 & 0.23 & 16.4 & 0.10 \\
\hline Whole & 540 & 0.84 & 2.88 & 2.99 & 8.54 & 1.41 & 47.2 & 0.65 & 0.98 & 0.49 & 50.0 & -0.16 \\
\hline
\end{tabular}

476 Abbreviations: $\mathrm{SH}=$ Sandhill, $\mathrm{HHF}=$ Hardwood Hammock and Forest, $\mathrm{PL}=$ Pineland, IP = Improved

477 Pasture, $\mathrm{DP}=$ Dry Prairie, $\mathrm{SD}=$ standard deviation, $\mathrm{CV}=$ coefficient of variation, skew. = skewness. 
479 Table 4. Estimated and derived parameters of semivariograms. The Matérn model was used to fit all 480 empirical semivariograms.

\begin{tabular}{llllll}
\hline Sites & $\begin{array}{l}\text { Nugget } c_{0} \\
\left(\log \left(\mathrm{kg} \mathrm{m}^{-2}\right)\right)^{2}\end{array}$ & $\begin{array}{l}\text { Partial sill } c_{1} \\
\left(\log \left(\mathrm{kg} \mathrm{m}^{-2}\right)\right)^{2}\end{array}$ & $\begin{array}{l}\text { Range parameter } r \\
(\mathrm{~m})\end{array}$ & $\begin{array}{l}\text { Smoothness } \\
v\end{array}$ & $\begin{array}{l}\text { Spatial } \\
\text { dependence }^{\mathrm{a}}\end{array}$ \\
\hline SH & 0.043 & 0.025 & 1.5 & 4.3 & 0.37 \\
HHF & 0.039 & 0.023 & 11.3 & 99.0 & 0.37 \\
PL & 0.071 & - & - & - & 0 \\
IP & 0.010 & 0.057 & 134.7 & 0.35 & 0.85 \\
DP & 0.034 & 0.018 & 9.4 & 0.32 & 0.35 \\
Average & 0.049 & 0.033 & 103.2 & $0.48^{\mathrm{b}}$ & 0.40
\end{tabular}

481 Abbreviations: $\mathrm{SH}=$ Sandhill, $\mathrm{HHF}=$ Hardwood Hammock and Forest, $\mathrm{PL}=$ Pineland, IP = Improved

482 Pasture, $\mathrm{DP}=$ Dry Prairie.

$483{ }^{a}$ Spatial dependence is defined as partial sill / sill.

484

485 
486 Table 5. Results for analysis of variance (ANOVA) models fitted by ordinary least square (OLS) and

487 generalized least square (GLS).

\begin{tabular}{|c|c|c|}
\hline Model & OLS & GLS $^{b}$ \\
\hline \multicolumn{3}{|c|}{$\beta$ parameters (class means, $\left.\log \left(\mathrm{kg} \mathrm{m}^{-2}\right)\right)$} \\
\hline Sandhill & $0.42 * \mathrm{D}$ & $0.45 * \mathrm{C}$ \\
\hline Hardwood Hammock and Forest & $1.38 * \mathrm{~A}$ & $1.43 * \mathrm{~A}$ \\
\hline Pineland & $0.53 * \mathrm{C}$ & $0.58 * \mathrm{BC}$ \\
\hline Improved Pasture & $1.16^{* \mathrm{~B}}$ & $1.13 * \mathrm{AB}$ \\
\hline Dry Prairie & $1.40 *^{\mathrm{A}}$ & $1.44 *^{\mathrm{A}}$ \\
\hline \multicolumn{3}{|l|}{$\theta$ parameters } \\
\hline Range (m) & - & 336.3 \\
\hline Partial sill $\left(\left(\log \left(\mathrm{kg} \mathrm{m}^{-2}\right)\right)^{2}\right)$ & - & 0.037 \\
\hline Nugget $\left(\left(\log \left(\mathrm{kg} \mathrm{m}^{-2}\right)\right)^{2}\right)$ & 0.065 & 0.032 \\
\hline \multicolumn{3}{|l|}{ Model summary } \\
\hline Degrees of freedom & 6 & 8 \\
\hline $\mathrm{AIC}^{\mathrm{a}}$ & 101.8 & 33.4 \\
\hline Log-likelihood $^{\mathrm{b}}$ & -44.9 & -8.7 \\
\hline
\end{tabular}

$488 \quad{ }^{a}$ AIC $=$ Akaike information criterion.

$489{ }^{\mathrm{b}}$ Model comparison test (likelihood ratio) shows the log-likelihood value from GLS model is significantly

490 higher than that from OLS model ( $p$-value $<0.0001)$.

$491{ }^{c}$ In GLS, exponential semivariogram model was used to account for the spatial autocorrelation of

492 samples.

$493 *$ denotes $t$ test of the parameters are significant $(p$-value $<0.001)$. Mean values that share a common

494 letter in superscripts are not significantly different at $\alpha=0.05$. 


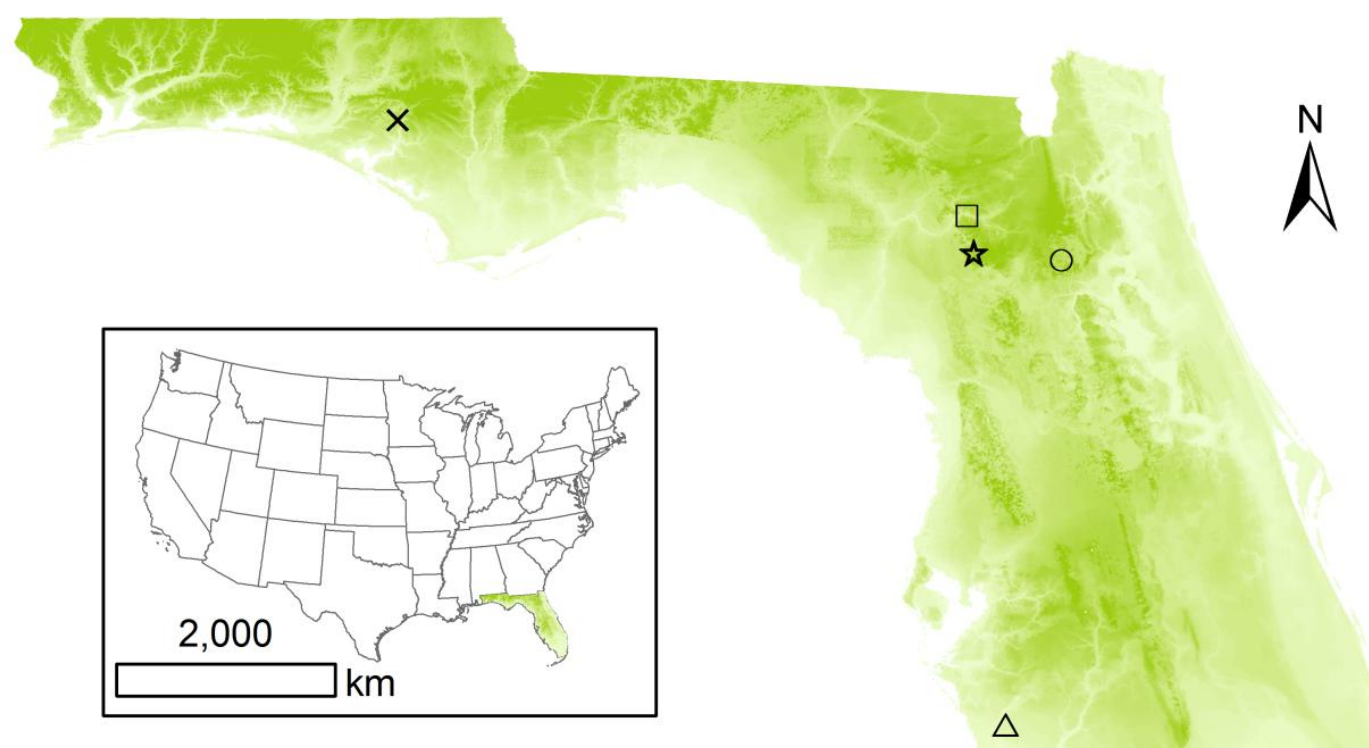

\section{Sampling Sites}

\section{- Sandhill \\ is Hardwood Hammock and Forest}

$\times$ Pineland

\section{Improved Pasture}

$\triangle$ Dry Prairie

Conterminous US boundary: United States Census Bureau, 2010, 1:500,000

Florida elevation: National Elevation Dataset, United States Geological Survey (30 m), 1999

\section{Elevation $(\mathrm{m})$}

106

0

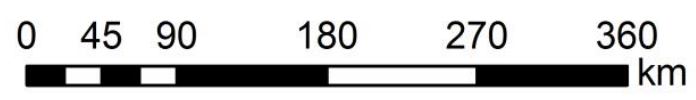

496 Fig. 1. Sampling sites under five land use and land cover classes and soil orders in Florida. 

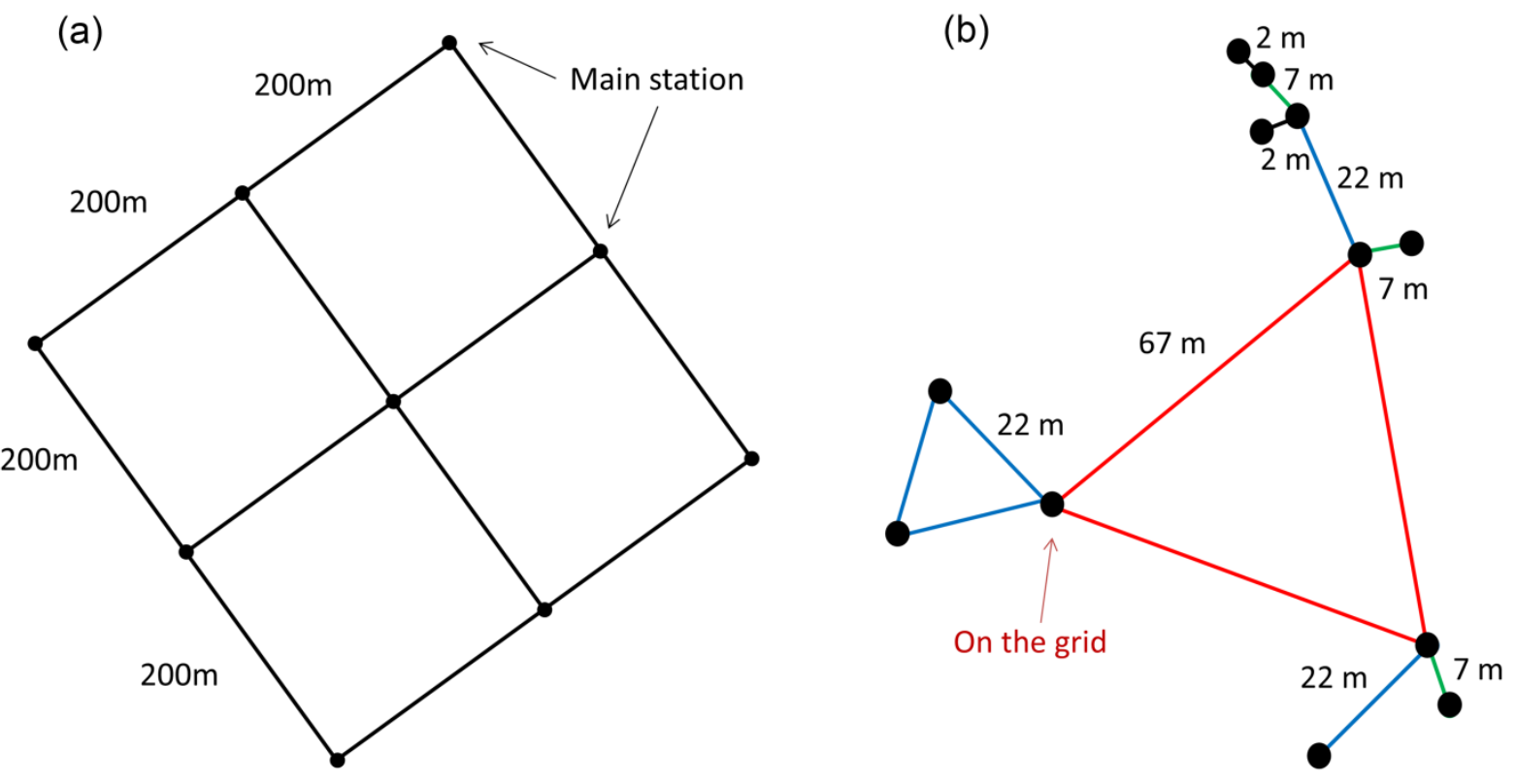

498

499 Fig. 2. The optimized unbalanced spatially nested scheme. (a) The layout of nine main stations. (b) The 500 sample deployment within one main station.

501 

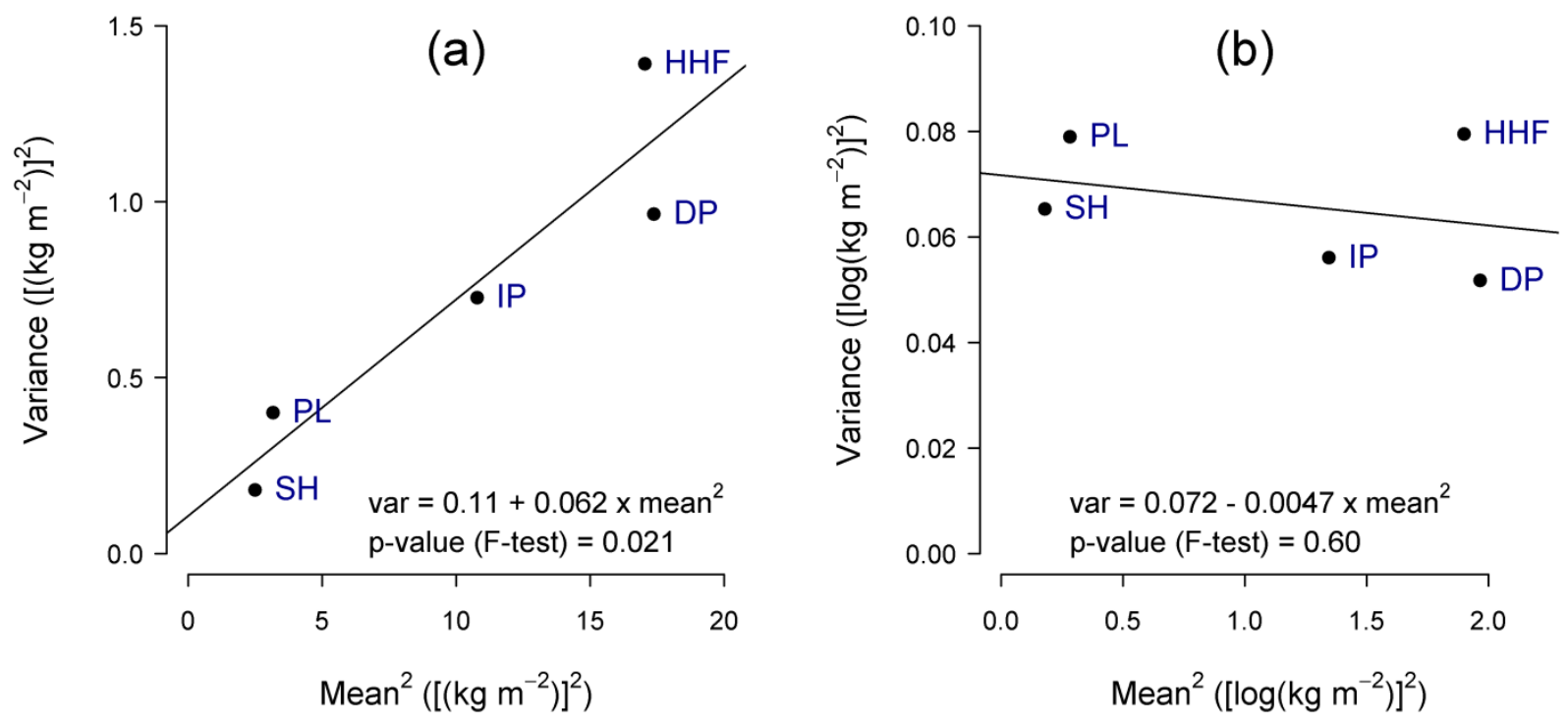

Fig. 3. The relationship between the variance and the squared mean of soil organic carbon (SOC): (a) raw

504 SOC data; (b) variance-stabilized (log-transformed) SOC data. SH = Sandhill, HHF = Hardwood Hammock

505 and Forest, $\mathrm{PL}=$ Pineland, $\mathrm{IP}=$ Improved Pasture, $\mathrm{DP}=$ Dry Prairie.

506 


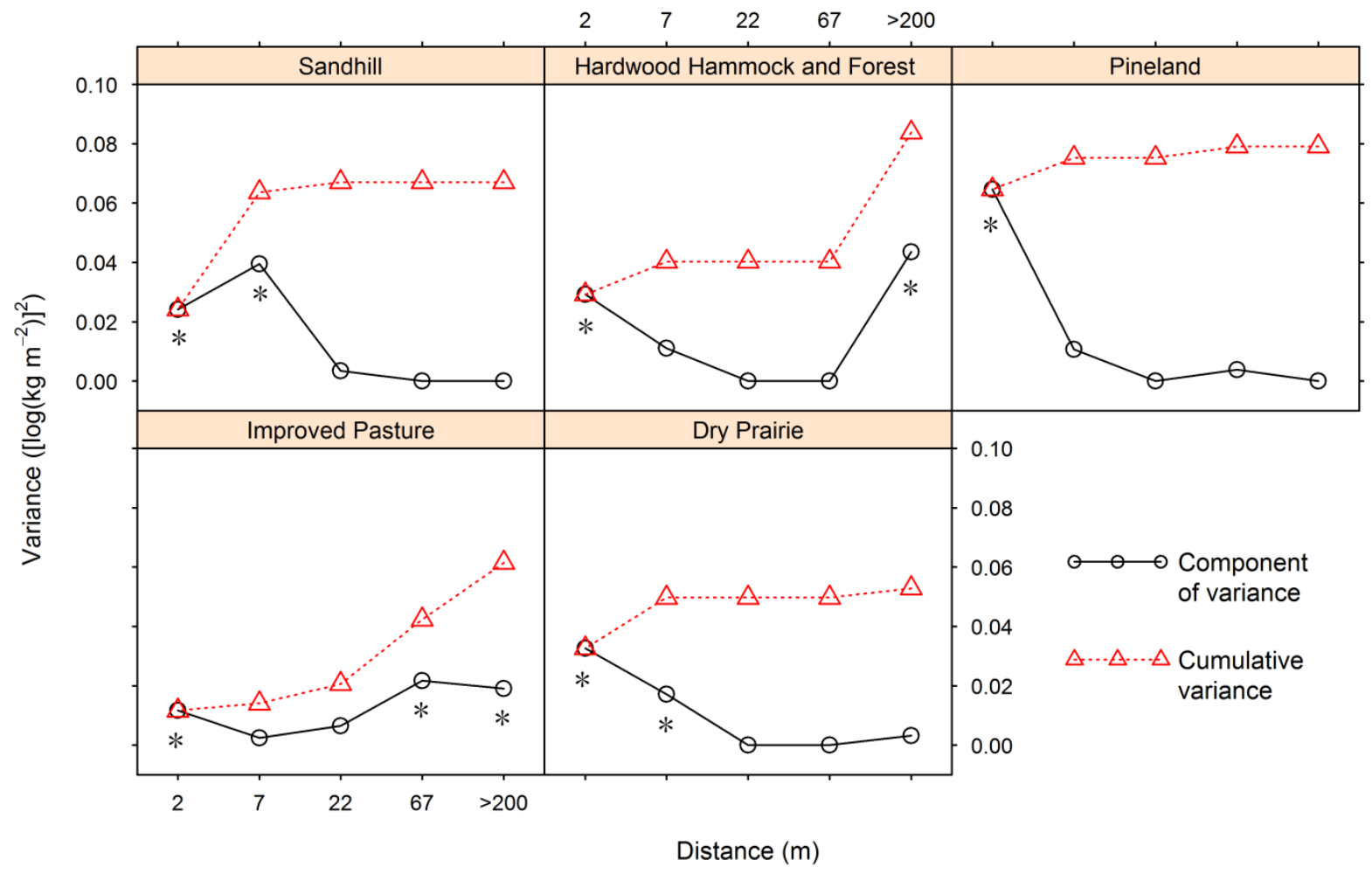

507

508 Fig. 4. Components and accumulated components of variance values for soil organic carbon at 0-20 cm

509 depth in five land use and land cover classes estimated by restricted maximum likelihood. Variance

510 components with * under them are significant at level of 0.05 .

511 

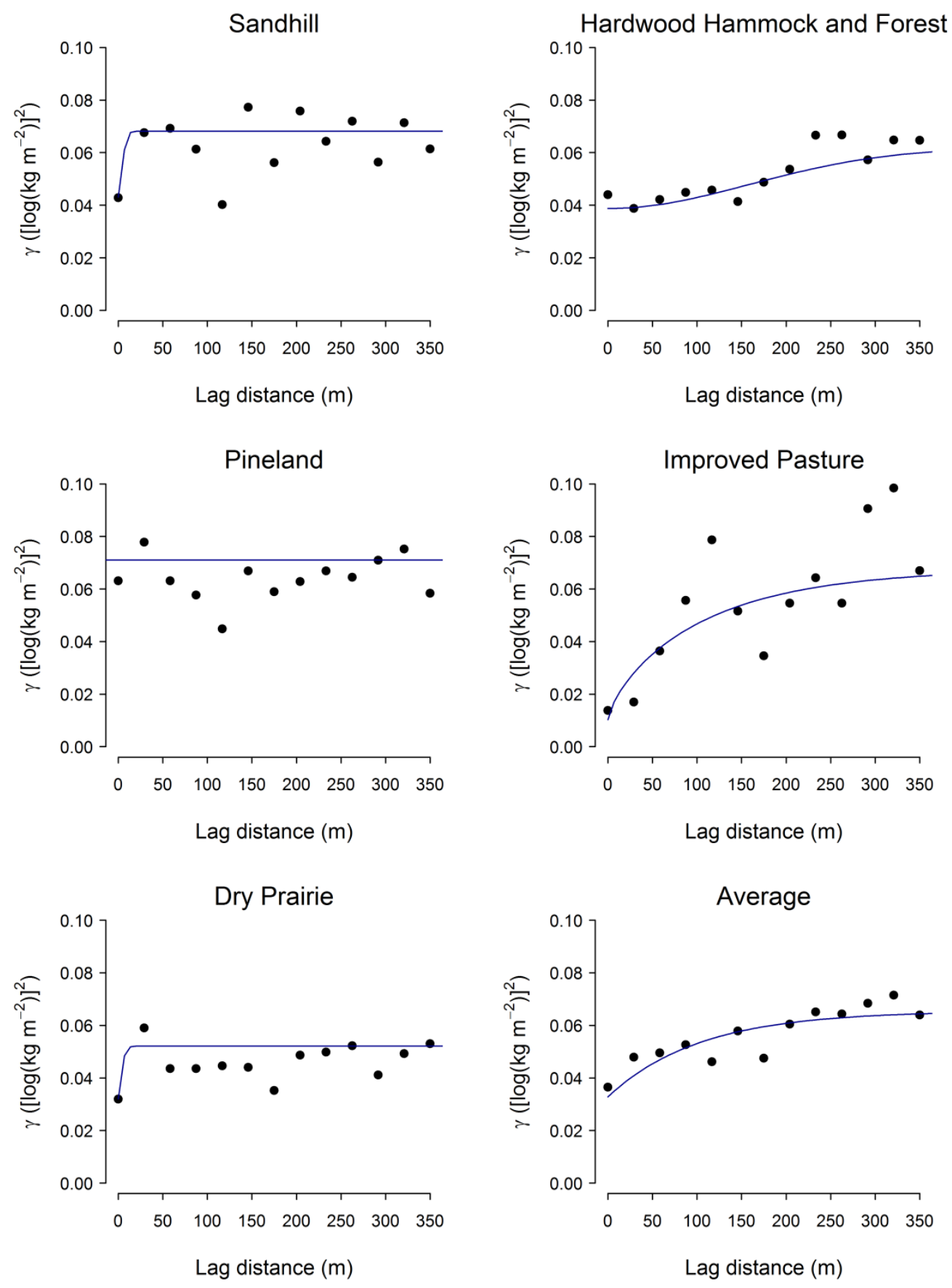

513 Fig. 5. Cressie-Hawkins robust estimators of semivariogram (dots) and Matérn semivariogram (solid lines)

514 with restricted maximum likelihood for soil organic carbon at 0-20 cm depth in five land use and land 515 covers. 